\title{
Associations of Traffic-Related Air Pollution with Children's Attention Spans: a Factor Analysis
}

\author{
Shunqin Wang ${ }^{1,2}$, Jinliang Zhang 3 , Jiangwu Yao ${ }^{1,4 *}$, Minquan Du ${ }^{1 * *}$ \\ ${ }^{1}$ School and Hospital of Stomatology, Wuhan University, Wuhan 430079, China \\ ${ }^{2}$ Xiamen Children's Hospital, Xiamen 361006, China \\ ${ }^{3}$ Division of Environmental Pollution and Health, Chinese Research Academy of Environmental Sciences, \\ Beijing 100101, China \\ ${ }^{4}$ Department of Oral Biology and Biomaterial, Xiamen Stomatological Research Institute, \\ Xiamen 361008, China
}

Received: 11 January 2016

Accepted: 19 March 2016

\begin{abstract}
To evaluate the associations between traffic-related air pollution (TRAP) and children's attention spans, an analysis was performed in a cross-sectional epidemiological study. Two primary schools were chosen based on the levels of traffic density and ambient air pollutants. School A is located in a clean area and School B in a polluted area. Two-hundred and eighty-two students from three third-grade classes (9-10 years of age) (School A, 136; School B, 146) participated in five computerized-based neurobehavioral tests. Neurobehavioral test results were used as the independent variables for component extraction by factor analysis, and two main compositions - visual memory factor and attention factor - were extracted. After controlling the potential confounding factors, we found that children from School B at the polluted area had lower scores of attention factor than those from School A in the clean area $(\beta=-0.300, p=0.016)$, and girls obtained higher scores than boys $(\beta=0.317, p=0.011)$. In conclusion, exposure to TRAP was significantly associated with decreased attention score of school-aged urban children, and the association was significantly more evident in boys than girls.
\end{abstract}

Keywords: child, air pollution, attention, factor analysis, vehicle emissions, psychophysiology

\section{Introduction}

It was reported that traffic-related air pollution (TRAP) was associated with a number of adverse health outcomes such as respiratory and cardio-vascular diseases

*e-mail: dentyjw@126.com

**e-mail: 21831168@qq.com
$[1,2]$. Although studies about potential neurobehavioral effects are still sparse, increasing evidence suggests that TRAP is a suspected developmental neurotoxin, especially for children [3]. Of the individual components of air pollution, carbon monoxide is a well-documented neurotoxin, and indoor exposure to this substance has now been linked to deficient neurobehavioral performance in children [4]. Ultrafine particles (UFP) are implicated in the pathophysiology of air pollution- 
related disease. Both animals and human studies have demonstrated that the brain may be affected by TRAP, particularly UFP [5]. Epidemiological studies have also reported associations between air pollution exposure and negative neurobehavioral outcomes in schoolaged children. Exposure to black carbon (a marker of TRAP) was associated with decreased cognitive scores for verbal and nonverbal intelligence and in memory at 8-11 years of age in a longitudinal cohort population of 202 children [6]. Sunyer [7] conducted a prospective study of children ( $\mathrm{n}=2,715$, aged 7 to 10 years) from 39 schools in Barcelona (Catalonia, Spain) exposed to high and low TRAP, paired by school socioeconomic index; and found that children attending schools with higher TRAP demonstrated less neurobehavioral development.

Attention problems are among the most common neurobehavioral conditions affecting youth. Inattention has implications for ongoing learning, social functioning, and academic achievement throughout life [8]. Attention deficit symptoms, a specific executive function domain, may contribute to more serious conditions, including conduct disorder and attention deficit/hyperactivity disorder (ADHD) [8, 9]. Although environmental factors have been implicated (e.g., prenatal and postnatal cigarette smoke; prenatal exposure to alcohol, cocaine, and heroin; childhood exposure to lead; and prenatal exposure to organophosphate pesticides) [10], to our knowledge few studies have examined the association between ambient air pollution and attention spans in children.

In 2005 we conducted a cross-sectional study and found that after controlling the potential confounding factors uusing ordinal logistic regression analysis, participants living in the polluted area showed poor performance on visual simple reaction time, continuous performance, digit symbol, pursuit aiming, and sign register [11]. Although these results were important to understand the associations between TRAP exposure and neurobehavioral disorders, while domain-specific neurobehavioral effects could not be identified because every test directly or indirectly assesses more than one domain of neurobehavioral function. In the present study, to explore the association between TRAP exposure and attention in children, a secondary analysis was carried out using factor analysis for our previous study.

\section{Material and Methods}

\section{Subjects}

Full details of the study used for this analysis are described in the primary manuscript [11]. Briefly, two primary schools were chosen based on traffic density and monitoring data of ambient air pollutants. School A was located in a clear area (monthly average $\mathrm{NO}_{2}=22 \mu \mathrm{g} / \mathrm{m}^{3}$, $\mathrm{PM}_{10}=80 \mu \mathrm{g} / \mathrm{m}^{3}$ ) and School B in a polluted area (monthly average $\left.\mathrm{NO}_{2}=7 \mu \mathrm{g} / \mathrm{m}^{33}, \mathrm{PM}_{10}=68 \mu \mathrm{g} / \mathrm{m}^{3}\right)$. Eight-hundred and sixty-one children (A: 431, B: 430) from second grade (8-9 years of age) and third grade (9-10 years of age) from two schools were selected to participate in manualassisted neurobehavioral tests, and 282 students from three third-grade classes (A: 136, B: 146) to participate in computer-based neurobehavioral tests. This analysis only included the 282 participants who finished computerbased neurobehavioral tests. Intelligence quotient (IQ) was measured using Raven's progressive matrices test and demographic data were collected though self-reporting questionnaires.

\section{Neurobehavioral Testing}

The five computer-based neurobehavioral tests were chosen from the Neurobehavioral Evaluation System (NES; Chinese version, 2000) [12], which were conducted to assess the participants' neurobehavioral functions, including line discrimination (LDT), visual retention (VRT), visual simple reaction time with preferred hand (VSRT-Prh), visual simple reaction time with nonpreferred hand (VSRT-Nprh), and continuous performance (CPT). All tests were conducted in a separate classroom guided by trained investigators.

\section{Statistical Analysis}

Continuous variables were summarized as mean \pm standard deviation (SD). For categorical variables, the percentages of subjects in each category were calculated. We used one-way analysis of variance (ANOVA) for continuous variables, and chi-square tests for categorical variables between two groups. Principal component analysis with varimax rotation was applied to the neurobehavioral ability index (NAI) [13] of the all test results by factor analysis. Eigenvalues reflect the amount of variance in the data that is explained by successive numbers of factors, and the traditional "eigenvalues $>1$ " rule was used as an indicator of the number of factors. The output from factor analysis provides "factor loadings," which show the contribution of an item to each factor (by convention, loadings $<0.50$ are usually ignored as being unimportant). Factor scores (which have a mean of zero and standard deviation of one) were generated from the model. Multivariate linear regression analysis was performed to examine the association between factor scores and 14 independent variables (selected according the results of univariate analysis): 3 continuous variables: age (years), intelligence quotient (IQ), bodymass index (BMI), and 11 categorical variables: TRAP exposure, gender, birthweight, secondhand smoke exposure, delivery method, open kitchen, computer use, household coal use, father education, vision, and breast-feeding. The backward method and 0.15 significance level were used to select variables in the model. All statistical analysis were carried out using SPSS software, version 13.0 (SPSS Inc., Chicago, USA). 
Table 1. Baseline data of the subjects between the two groups.

\begin{tabular}{|c|c|c|c|}
\hline & School A \# & School B\# & p-Value * \\
\hline Age (years) & $9.67 \pm 0.51$ & $9.60 \pm 0.41$ & 0.220 \\
\hline $\begin{array}{c}\text { Intelligence } \\
\text { Quotient (IQ) }\end{array}$ & $109.9 \pm 11.67$ & $108.77 \pm 14.41$ & 0.462 \\
\hline BMI & $17.51 \pm 5.35$ & $17.76 \pm 4.37$ & 0.674 \\
\hline \multicolumn{4}{|c|}{ Gender } \\
\hline Boy & $78(57.35)$ & $71(48.63)$ & 0.143 \\
\hline Girl & $58(42.65)$ & $75(51.37)$ & \\
\hline \multicolumn{4}{|c|}{ Vision $^{a}$} \\
\hline Normal & $111(81.62)$ & $105(71.92)$ & 0.055 \\
\hline Poor & $25(18.38)$ & $41(28.08)$ & \\
\hline \multicolumn{4}{|c|}{ Computer use $^{\mathrm{b}}$} \\
\hline Seldom & $41(30.83)$ & $38(26.21)$ & 0.394 \\
\hline Often & $92(69.17)$ & 107(73.79) & \\
\hline \multicolumn{4}{|c|}{ Secondhand smoke exposure ${ }^{c}$} \\
\hline Yes & $85(62.50)$ & $77(52.74)$ & 0.010 \\
\hline No & $51(37.50)$ & $69(47.26)$ & \\
\hline \multicolumn{4}{|c|}{ Natural labor } \\
\hline Yes & $105(80.77)$ & $103(72.54)$ & 0.110 \\
\hline No & $25(19.23)$ & $39(27.46)$ & \\
\hline \multicolumn{4}{|c|}{ Breast-feeding } \\
\hline$\geq 6$ months & $117(86.03)$ & $121(82.88)$ & 0.466 \\
\hline$<6$ months & $19(13.97)$ & $25(17.12)$ & \\
\hline \multicolumn{4}{|c|}{ Birth weight } \\
\hline$\geq 2.5 \mathrm{~kg}$ & $129(94.85)$ & $132(90.41)$ & 0.156 \\
\hline$<2.5 \mathrm{~kg}$ & $7(5.15)$ & $14(9.59)$ & \\
\hline \multicolumn{4}{|c|}{ Open kitchen } \\
\hline Yes & $22(16.18)$ & $15(10.27)$ & 0.142 \\
\hline No & $114(83.82)$ & $131(89.73)$ & \\
\hline \multicolumn{4}{|c|}{ Household coal use } \\
\hline Yes & $5(3.68)$ & $1(0.68)$ & 0.082 \\
\hline No & 131(96.32) & $145(99.32)$ & \\
\hline \multicolumn{4}{|l|}{$\begin{array}{l}\text { Father's } \\
\text { Education }\end{array}$} \\
\hline $\begin{array}{l}<\text { College/ } \\
\text { university }\end{array}$ & 121(92.37) & $100(68.49)$ & $<0.001$ \\
\hline $\begin{array}{l}\geq \text { College/ } \\
\text { university }\end{array}$ & $10(7.63)$ & $46(31.51)$ & \\
\hline
\end{tabular}

\#Data are number (percent) or mean \pm standard deviation $\$$ One-way analysis of variance or chi-square test ${ }^{\text {a}}$ Hypermetropia, myopia, astigmatism were identified as "poor"

bUsing computer $<2$ times/week was regarded as "seldom"

cAt least 1 family member smoking inside the house

\section{Results and Discussion}

\section{Results}

Analysis of demographic data. The baseline characteristics of the subjects are summarized in Table 1. Between the two groups, there are no significant differences in age, BMI, IQ, gender, computer use, delivery method, birth weight, and use of open kitchen, while we found significant differences in the children's fathers' education levels and secondhand smoke exposure, and borderline significances were also shown in vision $(p=0.055)$ and household coal use $(p=0.082)($ Table 1$)$.

Neurobehavioral tests results and ANOVA outcomes. Compared with the children from school A, those from school B had more wrong performances in the LDT test $(p=0.015)$ and larger CTS in the VSRTPrh test $(p=0.022)$ and VSRT-Nprh test $(p=0.004$; Table 2). The maximum correct performance time was significantly longer than that in school A children. Better results were present in all CPT test indexes. As for the complex evaluation index, namely NAI, children from school B had lower scores in all tests, while only CPT was of significant different between the two groups $(\mathrm{p}<0.05)$.

Factor analysis. Principal component analysis was used to NAI of the all test results by factor analysis. The value of the Kaiser-Meyer-Olkin measure of sampling adequacy (KMO) in the current study is 0.586 , which is over the threshold of 0.5. The result of Bartlett's test $(p<0.01)$ revealed that the five neurobehavioral tests are not independent, with a high level of correlation. Thus, factor analysis is suitable for the extraction of the component factors in the study.

The factor solution was determined by the number of factors generated with eigenvalues greater than 1 , as well as by theoretical considerations. NAIs of all tests were used as the independent variables for component extraction. Two factors had an eigenvalue greater than one that could be extracted to be the representative of all the tests (one eigenvalue is 1.651, the other is 1.072). The two-factor solution accounts for about $54.46 \%$ of the cumulative variance.

The relationship between the initial test results (NAI) and the extracted components was not obvious. Varimax rotation with maximum probability method was used to recompute these loadings on multiple factors. The results were shown in Table 3. According to the rotated component matrix, the two factors extracted the majority of information from different tests. The first factor (Factor 1) contains information mainly from two tests: VSRT-Prh (0.828) and VSRT-Nprh (0.789), which focuses on children's visual memory. The second factor (Factor 2) was mainly representative of the tests of LDT (0.787), VRT (0.542), and CRT (0.511), and reflects children's attention spans.

Table 4 shows the comparisons of factor scores between School A and School B. Children from A had higher scores for both Factor 1 (visual memory) and Factor 2 (attention), 
Table 2. Neurobehavioral tests and ANOVA outcomes.

\begin{tabular}{|c|c|c|c|c|c|c|c|c|}
\hline & \multicolumn{3}{|c|}{ School A } & \multicolumn{3}{|c|}{ School B } & \multirow{2}{*}{$\mathrm{F}$} & \multirow{2}{*}{ p-Value } \\
\hline & $\mathrm{N}$ & Mean & SD & $\mathrm{N}$ & Mean & SD & & \\
\hline \multicolumn{9}{|c|}{ Line Discrimination (LDT) } \\
\hline Correct & 133 & 6.744 & 2.162 & 141 & 6.943 & 2.425 & 0.511 & 0.475 \\
\hline Wrong & 133 & 13.917 & 5.689 & 141 & 15.901 & 7.501 & 6.028 & 0.015 \\
\hline Missed & 133 & 3.256 & 2.163 & 141 & 3.057 & 2.425 & 0.511 & 0.475 \\
\hline $\mathrm{NAI}^{\mathrm{a}}$ & 133 & 0.243 & 0.084 & 141 & 0.238 & 0.097 & 0.182 & 0.670 \\
\hline \multicolumn{9}{|c|}{ Retention Visual (VRT) } \\
\hline Correct & 135 & 6.956 & 1.799 & 146 & 6.897 & 1.867 & 0.071 & 0.790 \\
\hline Wrong & 135 & 2.089 & 1.479 & 146 & 2.281 & 1.503 & 1.162 & 0.282 \\
\hline Missed & 135 & 0.956 & 1.192 & 146 & 0.822 & 1.295 & 0.803 & 0.371 \\
\hline NAI & 135 & 0.649 & 0.193 & 146 & 0.646 & 0.196 & 0.017 & 0.897 \\
\hline \multicolumn{9}{|c|}{ Visual simple reaction time with preferred hand (VSRT-Prh) } \\
\hline Correct & 135 & 19.911 & 0.334 & 143 & 19.832 & 0.769 & 1.208 & 0.273 \\
\hline Maximum time of correct performance(sec) & 135 & 0.804 & 0.319 & 143 & 0.866 & 0.370 & 2.234 & 0.136 \\
\hline Minimum time of correct performance(sec) & 135 & 0.343 & 0.088 & 143 & 0.325 & 0.097 & 2.745 & 0.099 \\
\hline Average time of correct performance(sec) & 135 & 0.481 & 0.074 & 143 & 0.485 & 0.122 & 0.120 & 0.730 \\
\hline CTS & 135 & 0.109 & 0.069 & 143 & 0.131 & 0.091 & 5.297 & 0.022 \\
\hline NAI & 135 & 11.746 & 6.477 & 143 & 10.675 & 6.542 & 1.878 & 0.172 \\
\hline \multicolumn{9}{|c|}{ Visual simple reaction time with non-preferred hand (VSRT-Nprh) } \\
\hline Correct & 135 & 19.815 & 0.521 & 143 & 19.783 & 0.595 & 0.221 & 0.639 \\
\hline Maximum time of correct performance(sec) & 135 & 0.881 & 0.319 & 143 & 0.984 & 0.403 & 5.490 & 0.020 \\
\hline Minimum time of correct performance(sec) & 135 & 0.351 & 0.106 & 143 & 0.326 & 0.126 & 3.103 & 0.079 \\
\hline Average time of correct performance(sec) & 135 & 0.507 & 0.081 & 143 & 0.509 & 0.122 & 0.015 & 0.902 \\
\hline CTS & 135 & 0.126 & 0.072 & 143 & 0.154 & 0.091 & 8.283 & 0.004 \\
\hline NAI & 135 & 9.776 & 5.724 & 143 & 8.683 & 5.726 & 2.533 & 0.113 \\
\hline \multicolumn{9}{|c|}{ Continuous performance (CPT) } \\
\hline Correct & 133 & 29.541 & 1.125 & 146 & 28.925 & 3.293 & 4.216 & 0.041 \\
\hline Wrong & 133 & 2.609 & 2.744 & 146 & 4.082 & 5.403 & 8.005 & 0.005 \\
\hline Missed & 133 & 0.459 & 1.125 & 146 & 1.069 & $3 . .294$ & 4.120 & 0.043 \\
\hline NAI & 133 & 0.912 & 0.081 & 146 & 0.867 & 0.142 & 10.257 & 0.002 \\
\hline
\end{tabular}

${ }^{a}$ Neurobehavioral ability index (NAI) was an integrated index to express scores of computerized neurobehavioral testing directly computed by NES with the following formula: NAI $=[100-(\mathrm{Tt}+\mathrm{SD} \times \mathrm{WN})] /$ Correct/CTS, where Tt was the total time (in seconds), SD was the standard deviation of the correction coefficient $(0.116 \mathrm{sec} / \mathrm{time}), \mathrm{WN}$ was the number of wrong performance times, and Correct was the number of correct performance times [11, 13].

and borderline significance were $\mathrm{p}=0.059$ and $\mathrm{p}=0.092$, respectively.

Multivariate linear regression analysis. Table 5 presents the models of multivariate linear regression analysis. After controlling the potential confounding factors, IQ was significantly associated with the scores of Factor 1 (visual memory) and Factor 2 (attention), indicating higher IQ with higher factor scores. Being older was associated with a better score of Factor 1 (visual memory). Compared to boys, girls obtained higher scores for Factor 2 (attention) $(\beta=0.317, p=0.011)$. More importantly, the results showed that children in the polluted area had poorer Factor 2 scores (attention) ( $\beta=-0.300, p=0.016)$, suggesting that exposure to TRAP was significantly associated with children's decreased attention spans. 
Table 3. Results of factor analysis.

\begin{tabular}{|c|c|c|}
\hline \multirow{2}{*}{ Tests } & \multicolumn{2}{|c|}{ Factor Loadings } \\
\cline { 2 - 3 } & $\begin{array}{c}\text { Factor 1 } \\
\text { (visual memory) }\end{array}$ & $\begin{array}{c}\text { Factor 2 } \\
\text { (attention) }\end{array}$ \\
\hline Line Discrimination (LDT) & -0.223 & 0.787 \\
\hline Retention Visual (VRT) & 0.194 & 0.542 \\
\hline $\begin{array}{c}\text { Visual Simple Reaction } \\
\text { Time with preferred hand } \\
\text { (VSRT-Prh) }\end{array}$ & 0.828 & 0.014 \\
\hline $\begin{array}{c}\text { Visual Simple Reaction } \\
\text { Time with non-preferred } \\
\text { hand (VSRT-Nprh) }\end{array}$ & 0.789 & 0.133 \\
\hline $\begin{array}{c}\text { Continuous Performance } \\
\text { (CPT) }\end{array}$ & 0.368 & 0.511 \\
\hline
\end{tabular}

\section{Discussion}

Factor analysis was used in this study because it can identify the underlying component factors between the measured variables and the latent constructs, thereby allowing the formation and refinement of the theory. In the current study, two factors were extracted by factor analysis. Factor 1 reflects children's visual memory and Factor 2 reflects children's attention spans. By ANOVA, it was indicated that children from School A had higher scores for both Factor 1 (visual memory) and Factor 2 (attention), and there was borderline significance. Further study by multivariate linear regression analysis showed that, after controlling the potential confounding factors, children in the polluted area had a poorer score of Factor 2 (attention) $(\beta=-0.300, p=0.016)$ and girls obtained higher scores for Factor 2 (attention) compared to boys $(\beta=0.317, p=0.011)$.

The current secondary analysis showed that exposure to TRAP was significantly associated with the decrease in attention score of school-aged urban children. This finding is generally similar to those of some recent studies. YuehHsiu et al. [14] examined associations between black carbon (BC), a marker of traffic particles, and attention measurements ascertained that at 7-14 years of age among 174 children in a birth cohort based in Boston, Massachusetts found a positive association between higher $\mathrm{BC}$ levels and increased commission errors and slower reaction times, adjusting for child IQ, age, sex, blood lead level, maternal education, pre- and postnatal

Table 4. Comparison of factor scores between School A and School B.

\begin{tabular}{|c|c|c|c|}
\hline \multirow{2}{*}{ Factor } & \multicolumn{2}{|c|}{ Factor Score } & \multirow{2}{*}{ p-Value } \\
\cline { 2 - 3 } & School A & School B & \\
\hline $\begin{array}{c}\text { Factor 1 } \\
\text { (visual memory) }\end{array}$ & $0.119 \pm 0.934$ & $-0.112 \pm 1.049$ & 0.059 \\
\hline $\begin{array}{c}\text { Factor 2 } \\
\text { (attention) }\end{array}$ & $0.106 \pm 0.911$ & $-0.100 \pm 1.07$ & 0.092 \\
\hline
\end{tabular}

Table 5. Models of multivariate linear regression analysis.

\begin{tabular}{|c|c|c|c|c|}
\hline $\begin{array}{c}\text { Dependent } \\
\text { variables }\end{array}$ & $\begin{array}{c}\text { Variables } \\
\text { remaining in } \\
\text { the model }\end{array}$ & $\beta$ & $\mathrm{p}$-Value & $\mathrm{R}^{2}$ \\
\hline \multirow{5}{*}{$\begin{array}{c}\text { Factor 1 } \\
\text { (visual memory) }\end{array}$} & $\begin{array}{c}\text { Antelligence } \\
\text { Quotient } \\
\text { (IQ) }\end{array}$ & 0.019 & $<0.001$ & 0.581 \\
\cline { 2 - 5 } & $\begin{array}{c}\text { TRAP } \\
\text { exposure }\end{array}$ & -0.217 & 0.065 & \\
\cline { 2 - 5 } & $\begin{array}{c}\text { Nature } \\
\text { labour }\end{array}$ & 0.216 & 0.132 & \\
\cline { 2 - 6 } & $\begin{array}{c}\text { Intelligence } \\
\text { Quotient } \\
\text { (IQ) }\end{array}$ & 0.019, & $<0.001$ & \\
\hline \multirow{5}{*}{$\begin{array}{c}\text { Factor 2 } \\
\text { (attention) }\end{array}$} & $\begin{array}{c}\text { TRAP } \\
\text { exposure }\end{array}$ & -0.300 & 0.016 & 0.472 \\
\cline { 2 - 6 } & $\begin{array}{c}\text { Gender } \\
\text { labour }\end{array}$ & 0.317 & 0.011 & \\
\hline
\end{tabular}

tobacco smoke exposure, and community-level social stress. Siddique et al. [15] found a positive association between diagnosed attention deficit hyperactivity disorder (ADHD) and ambient particulate matter level in schoolaged children living in rural or urban India after controlling for potential confounders.

Boys had lower scores in Factor 2 than girls, suggesting that boys might be more susceptible to the effects of TRAP on the attention domain than girls. Although the importance of understanding sex differences in the neurotoxicity of a number of environmental chemicals has been increasingly underscored, few epidemiological studies have examined sex differences in toxicantassociated attention deficit symptoms in children. An analysis examining the association between environmental toxicants and ADHD using data from the National Health and Nutrition Examination Survey $(n=4,704)$ suggested that the association between prenatal maternal smoking and ADHD may be stronger in girls [16]. A recent study found that sex-stratified analysis demonstrated statistically significant associations between $\mathrm{BC}$ and both commission errors and in boys, but BC was not significantly associated with any of the CPT outcomes in girls [14]. This result of our study strengthens the conclusion of previous studies about sex differences in associations between TRAP.

As for potential mechanisms of the relationships between TRAP and children's attention, several studies have indicated that air pollution causes inflammation and oxidative stress in pulmonary tissue, with similar effects seen in the central nervous system (CNS) [17, 18]. In-vivo studies in rats have indicated that subchronic diesel exhaust exposure causes neuroinflammation and elevated early markers of neurodegenerative disease [19]. Chronic respiratory tract inflammation may lead to brain 
inflammation by altering levels of circulating cytokines, such as TNF- $\alpha$ and IL-1. These cytokines have the ability to up-regulatecyclooxygenase-2, a potent active mediator of inflammation, in capillary brain endothelium [20]. Furthermore, experimental data suggests that UFP can directly translocate into the CNS [21]. Therefore, it is necessary to further explore the mechanism of the association of traffic exhaust with children's attention spans in future research.

\section{Conclusions}

A strength of our study was that we selected the results of computer-based tests to secondary analysis, and the five computer-based tests are suitable for children to perform because children only needed one computer key to finish the test, which decreased the influence of computer familiarity and enhanced the validity of testing results. The other strength was that we identified the domain-specific neurobehavioral effects, namely attention domain, through factor analysis. The limitations of this current study are as follows: 1) a relatively small sample size, 2) only 14 covariates were considered in multivariate linear regression, and there is the possibility that other uncontrolled factors can have impact the results, and 3) only two study areas were involved in this study, which would impact the generality of the results.

In conclusion, exposure to TRAP was significantly associated with the decrease in attention score of schoolaged urban children, and the association was significantly more evident in boys than girls. Larger prospective studies are required to confirm this association.

\section{References}

1. JUNG D.Y., LEEM J.H., KIM H.C., KIM J.H., HAWANG S.S., LEE J.Y., KIM B.J., HONG Y.C., HONG S.J., HWON H.J. Effect of traffic-related air pollution on allergic disease: results of the children >s health and environmental research. Allergy Asthma Immunol. Res. 7 (4), 359, 2015.

2. BRUNEKREEF B., BEELEN R., HOEK G., SCHOUTEN L., BAUSCH-GOLDBOHM S., FISCHER P., ARMSTRONG B., HUGHES E., JERRETT M., VAN DEN BRANDT P. Effects of long-term exposure to traffic-related air pollution on respiratory and cardiovascular mortality in the Netherlands: the NLCS-AIR study. Res Rep Health Eff Inst. 139, 5, 2009.

3. GRANDJEAN P., LANDRIGAN P.J. Neurobehavioural effe cts of developmental toxicity. Lancet Neurol. 13, 330, 2014.

4. DIX-COOPER L., ESKENAZI B., ROMERO C., BALMES J., SMITH K.R. Neurodevelopmental performance among school age children in rural Guatemala is associated with prenatal and postnatal exposure to carbon monoxide, a marker for exposure to woodsmoke. Neurotoxicology. 33 (2), 246, 2012.

5. ZANOBETTI A., SCHWARTZ J. The effect of fine and coarse particulate air pollution on mortality: a national analysis. Environ Health Perspect. 117 (6), 898, 2009.

6. PEREA F.P., LI Z., WHYATT R., HOEPNER L., WANG
S., CAMANN D., RAUH V. Prenatal airborne polycyclic aromatic hydrocarbon exposure and child IQ at age 5 years. Pediatrics. 124(2), 195, 2009.

7. SUNYER J., ESNAOLA M., ALVAREZ-PEDREROL M., FORNS J., RIVAS I., LOPEZ-VICENTE M., SUADES-GONZALEZ E., FORASTER M., GARCIAESTEBAN R., BASAGARIA X., VIANA M., MORENO T., ALASTUEY A., ALASTUEY A., SEBASTIANGALLES N., NIEUWENHUIJSEN M., QUEROL X. Association between traffic-related air pollution in scho ols and cognitive development in primary schoolchildren: a prospective cohort study. PLoS Med. 12 (3), 1, 2015.

8. MAHONE E.M., SCHNEIDER H.E. Assessment of Attention in Preschoolers. Neuropsychol Rev. 22 (4), 361, 2012.

9. SPIRA E.G., FISCHE J.E. The impact of preschool inattention, hyperactivity, and impulsivity on social and academic development: a review. J Child Psychol. Psychiatry. 46 (7), 755, 2005.

10. YOLTON K., CORNELIUS M., ORNOY A., MCGOUGH J., MAKRIS S., SCHANTZ S. Exposure to neurotoxicants and the development of attention deficit hyperactivity diso rder and its related behaviors in childhood. Neurotoxicol Teratol. 44, 30, 2014.

11. WANG S.Q., ZHANG J.L., ZENG X.D., ZENG Y.M., WANG S.Q., CHEN S.Q. Association of traffic-related air pollution with children's neurobehavioral functions in Quanzhou, China. Environ. Health Perspect. 117 (10), 1612, 2009.

12. TAN L.L., DAI Z.Z., GAN Y.X. Neurobehavioral evaluation system and its application. Chin J Public Health Engineering. 2, 175, 2003 [In Chinese].

13. XU L.M., GU Y.Q., Lin J.B. Study on neurobehavioral ability indexes and their application. J Labour Med. 18, 101, 2001 [In Chinese].

14. YUEH-HSIU M.C., DAVID C.B., BRENT A.C., SHAWN A., RACHEL B., ROBERT O.W. Associations between traffic-related black carbon exposure and attention in a prospective birth cohort of urban children. Environ Health Perspect. 121 (17), 859, 2013.

15. SIDDIQUE S., BANERJEE M., RAY M.R., LAHIR T. Attention-deficit hyperactivity disorder in children chronically exposed to high level of vehicular pollution. Eur J Pediatr. 170 (7), 923, 2011.

16. BRAUN J.M., KAHN R.S., FROEHLICH T., AUINGER P., LANPHEAR B.P. Exposures to environmental toxicants and attention deficit hyperactivity disorder in U.S. children. Environ Health Perspect. 114 (12), 1904, 2006.

17. ALESSANDRINI F., BECK-SPEIER I., KRAPPMANN D., WEICHENMEIRER I., TAKENAKA S., KARG E., KLOO B., SCHULZ H., JAKOB T., MEMPEL M., BEHRENDT H. Role of oxidative stress in ultrafine particle-induced exacerbation of allergic lung inflammation. Am J Respir Crit Care Med. 179 (11), 984, 2009.

18. GERLOFS-NIJLAND M.E., VAN B.D., CASSEE F.R., SCHINS R.P., WANG K., CAMPBELL A. Effect of prolonged exposure to diesel engine exhaust on proinflammatory markers in different regions of the rat brain. Part Fibre Toxicol. 17, 7, 2010.

19. LEVESQUE S., TAETZSCH T., LULL M.E., KODAVANTI U., STADLER K., WAGNER A., JOHNSON J.A., DUKE L., KODAVANTI P., SURACE M.J., BLOCK M.L. Diesel exhaust activates and primes microglia: Air pollution, neuroinflammation, and regulation of dopaminergic neurotoxicity. Environ Health Perspect. 119 (9), 1149, 2011. 
20. CAMPBELL A. Inflammation, neurodegenerative diseases, and environmental exposures. Ann NY Acad Sci. 1035, 117, 2004.

21. ALLEN J.L., LIU X., WESTON D., PRINCE L., OBERDÖRSTER G., FINKELSTEIN J.N., JOHNSTON C.J., CORY-SLECHTA D.A. Developmental exposure to concentrated ambient ultrafine particulate matter air pollution in mice results in persistent and sex-dependent behavioral neurotoxicity and glial activation. Toxicol Sci. 140 (1), 160, 2014. 